\title{
INFORME A LA COMISIÓN ESPECIAL DE MODERNIZACIÓN DEL RÉGIMEN POLÍTICO CHILENO SOBRE PERFECCIONAMIENTO DEL SISTEM A CONSTITUCIONAL, CON ESPECIAL ÉNFASIS EN EL TIPO DE GOBIERNO
}

Humberto Nogueira Alcalá

1. EL PRESIDENCIALISMO, SUS VENTAJAS Y DEBILIDADES

El régimen presidencial podemos conceptualizarlo señalando que es un régimen democrático representativo de separación rígida de poderes cuyo Ejecutivo está constituido por un Presidente de la República, elegido por sufragio universal, quien es Jefe de Estado, Jefe de Gobierno y de la administración, siendo los Ministros de Estado nombrados y revocados por el primero, quienes no son responsables políticamente ante el Parlamento.

La ventaja del sistema presidencialista es la estabilidad del Ejecutivo y la concentración de la capacidad ejecutiva en un solo órgano unipersonal que goza de amplia independencia del Parlamento, maximizando la rapidez y la coherencia de las decisiones. Asimismo, en América Latina, el Presidente se constituye en el padre y guía moral del país, lo que se enraíza con la presencia anterior y caudillos y estos en la realidad de los capitanes generales en la colonia, en el caso chileno.

La institución presidencial en Chile, es la que ha juzgado un rol predominante en la construcción del Estado, ha ayudado a mantener la identidad, la continuidad y la integración de la sociedad.

$1 \quad$ El autor es Doctor en Derecho Constitucional, Universidad Católica de Lovaina la Nueva. Profesor Titular de Derecho Constitucional y Director del Centro de Estudios Constitucionales de Chile. Miembro Asociado de la A cademia Internacional de Derecho Comparado. Vicepresidente del Instituto Iberoamericano de Derecho Procesal Constitucional. Presidente de la Asociación Chilena de Derecho Constitucional. 
El presidencialismo en sus diversas variantes de presidencialismo puro, atenuado 0 parlamentarizado entrega la jefatura de Estado y de gobierno en una sola persona, lo que si bien asegura la estabilidad del Ejecutivo, genera una alta concentración del poder en una sola persona, generando en sistemas democráticos con pluripartidismo un juego de suma cero, en que el ganador de las elecciones presidenciales concentra todo el poder en sus manos. ${ }^{2}$ El Presidente cuenta con un cheque en blanco para desarrollar su proyecto de gobierno personal, donde el programa presentado al electorado se desvanece fácilmente, no existiendo mecanismos institucionales para exigir su cumplimiento.

El Presidente de la República puede cambiar de orientación política el gobierno discrecionalmente, sin que nadie pueda impedírselo o contenerlo. Tal perspectiva alienta el caudillismo y un liderazgo sin contrapeso y sin conciencia de poder limitado que posibilita la institucionalidad presidencialista.

El presidencialismo surge y se ha desarrollado en una cultura paternalista, donde el Presidente de la República es el "pater familia", en el que se delega el poder para que actúe según su prudencia política, lo cual potencia la tendencia al mesianismo político que produce desestabilización y crisis democrática, además de ser fuente de instalación de proyectos autoritarios, ${ }^{3}$ como ha sido y es bastante corriente en América Latina, lo que se acentúa con las reelecciones inmediatas de los presidentes en el poder, los casos de Fujimori en Perú y del Presidente Chávez en Venezuela, ${ }^{4}$ para tomar dos extremos, son bastante elocuentes en la materia, que buscaban concentrar el poder en sus manos y perpetuarse en el mismo, en el segundo caso la perspectiva se desvaneció temporalmente por la pérdida del referéndum de diciembre de 2007, pero permanece latente.

El régimen presidencialista está en hacer asumir a una sola persona el rol del Jefe de Estado, símbolo de la integración nacional y de la estabilidad institucional, y por otra parte, el conductor de la política contingente que representa sólo a un sector o parcialidad. Es imposible cumplir bien ambas funciones, algunos harán prevalecer su rol del jefe de Estado con el consiguiente perjuicio para la conducción de la política contingente o darán primacía a esta segunda, deteriorando su rol de Jefe de Estado integrador y símbolo de la unidad y continuidad nacional.

A simismo, el parlamento constituye un órgano debilitado que no permite contrapesar al gobierno, generándose un régimen de hegemonía presidencial desequilibrado con rasgos más o menos autoritarios.

2 Ver Linz, Juan. "Los peligros del presidencialismo", en Linz, Juan y otros. Reformas al presidencialismo en América Latina. ¿Presidencialismo vs. Parlamentarismo? Ed. Comisión Andina de Juristas y Editorial Jurídica Venezolana; Caracas, 1993, pp. 33 y ss.

3 Ver, Linz, Juan y Valenzuela, Arturo (eds.). The failure of presidential democracy. The Johns Hopkins University Press. Baltimore, 1994.

4 ARISmendi A., Alfredo. "Separación de los poderes y el sistema presidencial", en Casal H., J.M.; A rismendi A., A. y Carrillo A., C. (coordinadores). Tendencias A ctuales del Derecho Constitucional. Homenaje a Jesús María Casal Montbrun. Ed. Universidad Central y Universidad Católica Andrés Bello, Caracas, 2007. 
Asimismo, en el caso que el Presidente de la República no cuente con mayoría parlamentaria, lo que ocurre frecuentemente en sistemas políticos con multipartidismo, ${ }^{5}$ pese a todos sus poderes jurídicos, solamente se convierte en un administrador del sistema sin poder procesar y cumplir su programa de gobierno, salvo que desarrolle una negociación proyecto a proyecto en el Congreso Nacional. Si la oposición mayoritaria en el parlamento no está disponible para negociar con el gobierno producto de su distinta concepción de la tarea del gobierno o por desarrollar una oposición obstruccionista de desgaste para sumir la alternancia, el sistema político se bloquea y paraliza, ${ }^{6}$ con el consiguiente peligro de crisis del sistema político institucional en su conjunto, como ocurrió en Chile en 1973 y en diversas otras experiencias latinoamericanas.

El sistema presidencialista por la acumulación de poderes hegemónicos en manos del Jefe de Estado se juega a las virtudes y defectos del Presidente, su lealtad y prácticas democráticas, su capacidad de gobierno y administración, su capacidad de negociación y de liderazgo, su honestidad, entre otros aspectos. La ausencia o escasez de virtudes del Jefe de Estado pueden paralizar el sistema político, iniciar el desarrollo y/o profundización de crisis económicas, sociales y políticas, como ha ocurrido históricamente en Argentina, en Brasil, en Bolivia y en Ecuador, para señalar algunos ejemplos relativamente recientes de nuestro continente.

El sistema presidencialista facilita las conductas de rigidez y de irresponsabilidad de los actores políticos, no generando un medio adecuado para las tendencias al compromiso, la negociación y a la responsabilidad. En efecto, el Presidente es elegido por un período fijo y determinado de tiempo, el cual no necesita, por tanto, una vez elegido, de preocuparse por mantener y alcanzar una mayoría parlamentaria de apoyo, la cual es indiferente para su posición institucional. Por otra parte, los partidos políticos que apoyaron al candidato presidencial, se van distanciando del Presidente para evitar el desgaste político de la acción gubernamental a medida que se acerca la próxima elección parlamentaria. Finalmente, la oposición política puede extremar su polarización y acción demagógica, teniendo claro que nada hará cambiar su situación institucional durante el mandato presidencial en curso; desarrollando una acción obstruccionista en el parlamento, que muchas veces produce un juego de suma cero. No se favorece las relaciones de cooperación entre el Gobierno y el Parlamento, especialmente cuando existen partidos organizados y disciplinados.

Así un Presidente que concreta una fuerte concentración de poder de gobierno con apoyo electoral minoritario o con pérdida de apoyo electoral durante el mandato, por tanto, con una situación política de ser minoría en el electorado y en el parlamento, genera una crisis y una confrontación polarizada que frecuentemente ha derivado

Ver, Mainwaring, Scott. "Presidencialismo, multipartidismo y democracia: la difícil combinación", en Revista de Estudios Políticos N 88/1995, Madrid, 1995.

6 Ver Alcántara Sáez, Manuel y Sánchez López, Francisco. "Veto, insistencia y control político en América Latina: una aproximación institucional", en Perfiles Latinoamericanos, Año 9 N1 19, México 2001. 
en A mérica Latina en crisis institucionales y potenciado formas de autocracias autoritarias en diversas modalidades.

El bloqueo institucional no tiene solución en el sistema presidencialista en tales circunstancias, salvo la destitución presidencial por acusación constitucional, lo que requiere configurar las causales jurídicas constitucionales y las mayorías calificadas necesarias para dicho proceso que son muy difíciles de alcanzar y de lo cual hay pocos ejemplos.

Asimismo, el régimen presidencialista no ofrece incentivo alguno al compromiso político entre el Jefe de Estado y las fuerzas políticas con representación parlamentaria opositora, ya que el objetivo de estas últimas es desgastar al gobierno para reemplazarlo. Un Jefe de Estado minoritario y obstinado puede mantenerse en el gobierno hasta el término del periodo presidencial pese a ser doblemente minoritario en el cuerpo electoral y en el parlamento, no existiendo la posibilidad institucional de forzar un cambio en la política gubernamental. En Chile puede mantenerse en funciones con el apoyo de un tercio más uno de los senadores en ejercicio.

El sistema de partidos en el presidencialismo tiene una clara orientación hacia partidos electorales y clientelísticos, pragmáticos y populistas, sin un desarrollo programático serio, ya que ellos están destinados a ganar elecciones, pero no a asumir una función responsable de gobierno alternativo en forma institucionalizada.

Frente a esta realidad, la academia se divide en una línea que propone mantener el tipo de gobierno presidencial, despojándolo de los elementos que hegemonizan el poder en manos del Presidente de la República, reequilibrándolo, ${ }^{7}$ quienes buscan el reemplazo por el régimen parlamentario ${ }^{8} 0$ quienes rescatando instituciones arraigadas en la cultura política latinoamericana como la figura del Presidente de la República, la mantienen en el marco del tipo de gobierno semipresidencial. ${ }^{9}$

7 Ver CARPIZo, Jorge. "México ¿sistema presidencial o parlamentario?", en Cuestiones Constitucionales, julio-diciembre de 1999, M éxico, pp. 49 y ss. Colomer, Josep y NeGretro, Gabriel. "La gobernanza de la democracia presidencial", en Mora-Donatto, Cecilia (coord.). Relaciones entre Gobierno y Congreso. Memoria del VII Congreso Iberoamericano de Derecho Constitucional. Ed. Instituto de Investigaciones Jurídicas, UNAM, México, 2002, pp. 79-124. Nohlen, Dieter y FERnÁndez, M ario. (eds.). El presidencialismo renovado. Ed. Nueva Sociedad, Caracas, 1998. Valadés, Diego. El control del poder. Ed. UNAM, México, 1998.

8 LINZ, Juan. "Democracia: presidencialismo o parlamentarismo ¿Hace alguna diferencia?", en Godoy, Óscar. Hacia una Democracia moderna. La opción parlamentaria. Ediciones Universidad Católica de Chile, Santiago, 1990, pp. 46 y ss. Godor, Óscar. "El régimen parlamentario: una opción política para Chile"; en Godoy, Óscar. En Hacia una Democracia moderna. La opción parlamentaria. Ediciones Universidad Católica de Chile, Santiago, 1990, pp. 11 y ss. LIJPHART, A. "Presidencialismo y democracia de mayoría", en Godoy, Óscar. En Hacia una Democracia moderna. La opción parlamentaria. Ediciones Universidad Católica de Chile, Santiago, 1990, pp. 111 y ss.

9 NoguelRA A., Humberto. A nálisis crítico del presidencialismo y consideraciones sobre una alternativa de régimen semipresidencial para Chile. D/7/86. Ed. ICHEH, Santiago, 1986. Cum PLIDO C., Francisco. "Análisis del régimen semipresidencial en Chile", en Godoy, Óscar (editor). Cambio de régimen político. Ed. Universidad Católica de Chile, Santiago, 1992, pp. 117-140. SARTORI, G. "Niether Presidentialism or parliamentarism", en Valenzuela, A. (comp.) Presidential or parlamentary democracy. John Hopkins 


\section{UNA ALTERNATIVA VIABLE PARA CHILE: EL SEM IPRESIDENCIA LISMO}

La tradición y cultura nacional no permite, a nuestro juicio, pensar en el establecimiento de un régimen parlamentario monista en nuestro país por razones culturales, históricas y políticas. Ello no significa, por otra parte, contentarse con una ligera atenuación de las atribuciones del Presidente de la República, mediante el nombramiento de un M inistro como Jefe de Gabinete, en el cual el Presidente delegue algunas funciones administrativas, lo que requiere de la sola modificación de ciertas disposiciones de la Ley de M inisterios, o la mayor frecuencia de explicaciones de los M inistros a las Cámaras para responder interrogantes sobre la política gubernamental, situación que ya está prevista en el sistema chileno. Esta concepción no resuelve el control institucional total del Poder Ejecutivo por el Presidente de la República con sus posibles cualidades y defectos, quedando el régimen político extremadamente dependiente de ellos; tampoco soluciona la falta de flexibilidad del sistema para absorber y resolver crisis políticas graves; no logra generar un polo alternativo de poder en el Ejecutivo que pueda funcionar como «fusible» o canal de iniciativas de la mayoría parlamentaria opositora; finalmente, ella tampoco contribuye a generar relaciones de diálogo, compromiso y responsabilidad institucional de los diversos actores y fuerzas políticas.

El diagnóstico efectuado, si es correcto, lleva necesariamente a reflexionar sobre otras opciones de regímenes democráticos que manteniendo la figura presidencial en un esquema institucional menos rígido o más flexible, que sea capaz de mantener en una relación de colaboración y armonía al gobierno y la mayoría parlamentaria; de superar democráticamente los desacuerdos políticos, sin afectar el funcionamiento democrático, impidiendo así los bloqueos de poder; que supere los fuertes desequilibrios entre órganos políticos del Estado y cree una conciencia de poder limitado en los órganos constitucionales; que posibilite la desconcentración del poder al interior del gobierno; y que favorezca en las autoridades y en las fuerzas de gobierno y oposición conductas más responsables.

Gobierno Fuerte no es el que tiene concentrado en sus manos muchas atribuciones, sino aquel que tiene legitimidad y el apoyo político suficiente para realizar en forma efectiva su programa de gobierno, lo que requiere mayoría parlamentaria. Un régimen semipresidencial tiene así gobiernos más fuertes que los regímenes presidencialistas, dotados de mayor eficiencia y eficacia. La concentración del poder en el Presidente sin mayoría parlamentaria, como ocurre a menudo en el régimen presidencialista, constituye comparativamente el gobierno más débil y menos eficiente

University Press, Baltimore, 1990; traducción en Godoy, Óscar (ed.). Cambio de régimen político. Ediciones Universidad Católica de Chile, Santiago, 1992. pp. 37-53. A RRIAGADA H., Genaro. "Después de los presidencialismos ...¿Qué?", en Godoy, Óscar (ed.). Cambio de régimen político. Ediciones Universidad Católica de Chile, Santiago, 1992, pp. 57-101. Nino, Carlos Santiago. Fundamentos de Derecho Constitucional. Ed. Astrea, Buenos Aires. 1992, pp. 619-657. PAoLI, Francisco. La transición incompleta, Granados Chapa Editores, México, 2006. 
El tipo de gobierno semipresidencial permite asegurar todos los objetivos señalados en el párrafo anterior, se caracteriza por su flexibilidad y por sus modalidades alternativas de funcionamiento presidencial y semipresidencial.

Podemos así conceptualizar el régimen semipresidencial, como un régimen político democrático representativo de separación flexible de poderes con un Ejecutivo dualista, siendo uno de sus órganos el Jefe de Estado, quien es un Presidente de la República elegido por sufragio universal que tiene un conjunto de atribuciones de moderación y arbitraje político que son ejercidos sin refrendo ministerial, y el otro órgano es el gobierno, dirigido por un Primer M inistro, el cual tiene la responsabilidad de realizar el programa de gobierno, conduciendo el gabinete ministerial, el que debe contar con el apoyo o tolerancia política de la mayoría parlamentaria, la cual puede destituirlo a través de un voto de censura, que puede adquirir la modalidad de voto de desconfianza constructivo.

El punto central del régimen semipresidencial es una buena técnica de delimitación de atribuciones entre el Presidente de la República y el gobierno conducido por el Primer Ministro para evitar una posible fuente de conflictos, y si este se produce el sistema normativo constitucional ofrezca una solución jurídica clara y arbitrajes políticos adecuados.

El sistema semipresidencial ha funcionado bien en sistemas con pluripartidismo (Finlandia, Francia, Portugal) y con sistemas electorales tanto proporcionales (Finlandia y Portugal) como con sistemas mayoritarios uninominales a dos vueltas (Francia). En países con un sistema de partidos ya desarrollados (Finlandia) o con sistema de partidos emergente después de periodos autocráticos (Polonia, Portugal y Rumania, entre otros).

El atractivo de esta modalidad de gobierno está dada por el hecho de una fórmula institucional, que dentro de un régimen constitucional democrático, mantiene la institución de un Presidente de la República electo directamente por la ciudadanía, quien es jefe de Estado y dispone de atribuciones políticas y gubernativas importantes, además de potestades de regulación y arbitraje del juego político, posibilitando la conducción y orientación del gobierno en la hipótesis de que, además de ser electo por la mayoría del cuerpo político de la sociedad, cuente con una mayoría parlamentaria que lo reconozca también como su líder.

El régimen de gobierno se comporta en esta hipótesis como un régimen presidencial, donde el Presidente de la República conduce el gobierno dentro de un sistema institucional más equilibrado y con controles y resguardos institucionales en caso de crisis más efectivos que el presidencialismo latinoamericano.

Esta hipótesis de aplicación del sistema institucional posibilita una gobernanza o gobernabilidad adecuada y posibilita una mayor satisfacción en la ciudadanía, a la vez que posibilita superar los bloqueos institucionales del presidencialismo, la escalada del conflicto entre Presidente y Parlamento, en definitiva la ingobernabilidad que pro- 
duce el enfrentamiento sin solución entre Presidente de la República y parlamento en el presidencialismo.

El tipo de gobierno semipresidencial presenta la ventaja institucional de la flexibilidad de posibilitar siempre un funcionamiento del régimen democrático con un gobierno que sea expresión de la mayoría parlamentaria, retrotrayéndose el Presidente de la República a la tarea de arbitraje y regulador del juego político, cuando este no sea el líder de la mayoría parlamentaria, asumiendo el Primer M inistro la tarea plena de conducción del gobierno dentro de los cauces del estado constitucional democrático.

El sistema semipresidencial por su flexibilidad posibilita la superación dentro del régimen institucional democrático de todas las hipótesis de conflicto institucional insuperables dentro del presidencialismo, lo que constituye una ventaja enorme frente a este último en situaciones de conflicto o en casos de un Presidente de la República carente de capacidad de gobierno o de virtudes democráticas, el que haya perdido la confianza del cuerpo político de la sociedad o que su coalición gubernamental haya hecho crisis.

El sistema semipresidencial desarrolla una pedagogía para los liderazgos políticos de poder limitado y controlado, lo que constituye una contribución significativa a un cambio de cultura política, que posibilite dejar atrás los mesianismos y caudillismos salvadores de la patria, favoreciendo una cultura democrática de acuerdos y de cooperación.

A simismo, cualquiera sea la hipótesis de funcionamiento del tipo de gobierno semipresidencial fortalece la institución del parlamento o Congreso Nacional (uni o bicameral), reequilibrando el sistema institucional, antes desbordado por la hegemonía presidencial.

El sistema semipresidencial puede funcionar con un sistema unicameral (Finlandia, Islandia, Portugal) o bicameral (Francia) como ocurre en la práctica. En la realidad chilena, hoy parece no justificarse más que en la inercia el bicameralismo existente, las diferenciaciones de funciones de ambas cámaras solo se produce en la fiscalización del gobierno, ambas cámaras son igualitarias en el proceso legislativo. La única diferencia específica real existente entre diputados y senadores es la jerarquización de la carrera política específica.

Puede señalarse que un Congreso dividido en dos cámaras favorece el eventual uso de una cámara contra la otra por el Presidente en el proceso legislativo, debilitando al parlamento frente al ejecutivo. La posible mejor técnica legislativa del bicameralismo se puede compensar por el establecimiento de dos secciones de la Cámara única en el análisis de los proyectos de ley, con sus respectivas comisiones especializadas y comisiones mixtas para resolver los conflictos, como ocurre en el derecho comparado en el Althing de Islandia o en Finlandia con el Landtag.

El sistema semipresidencial favorece un fortalecimiento del rol jugado por el sistema de partidos políticos, como asimismo induce al desarrollo de partidos más progra- 
máticos y menos pragmático electoralistas. En efecto, los distintos partidos tienen la posibilidad de ingresar al gobierno o reemplazarlo ante cambios de la voluntad popular o crisis de las coaliciones de gobierno, lo que exige a los partidos de oposición una capacidad de ser alternativa de gobierno, lo que requiere permanente capacidad de ofrecer alternativas reales, concretas y eficaces a las políticas gubernamentales.

Por otra parte, el sistema semipresidencial tiene una mayor propensión a gobiernos que tomen decisiones efectivas, representativas y que expresen una mayor satisfacción en la ciudadanía con mayor frecuencia que en los regímenes presidencialistas, por la lógica institucional, en que las decisiones gubernamentales explicitan la confluencia del gobierno y la mayoría parlamentaria y la tendencia a la colaboración entre ambos órganos constitucionales.

Como hemos adelantado consideramos que el arreglo institucional del tipo de gobierno semipresidencial presenta ventajas comparativas para una toma efectiva de decisiones gubernamentales y con una más amplia satisfacción ciudadana por las decisiones adoptadas, ya sea en la hipótesis de gobierno unificado o dividido, ya que el gobierno siempre opera en armonía con la voluntad ciudadana expresada en la elección parlamentaria, que es el órgano más representativo del cuerpo político de la sociedad, el que incluye la representación de los diversos sectores políticos de la sociedad en forma más o menos fidedigna y proporcionada.

\section{ESTATUTO CONSTITUCIONAL DEL PRESIDENTE DE LA REPÚBLICA}

\subsection{El periodo presidencial}

Un sistema semipresidencial y su lógica de posibilitar un gobierno unificado si la voluntad ciudadana así lo determina, posibilitando un funcionamiento presidencial según la primera hipótesis que se describe más adelante, requiere periodos presidenciales y parlamentarios que no sean demasiado prolongados, siendo el mandato presidencial el mismo que el parlamentario, ${ }^{10}$ los periodos debieran tender a coincidir en el caso de los diputados y Presidente de la República.

El periodo presidencial debiera mantenerse en cuatro años, con la posibilidad de reelección inmediata por una sola vez, en el caso de modificar el presidencialismo en semipresidencialismo. En un esquema institucional semipresidencial no presenta inconvenientes la eventual reelección inmediata del Presidente de la República para el periodo siguiente por una sola vez, si la ciudadanía así lo determina democráticamen-

10 Esta es la perspectiva que tuvo que asumir Francia, que disminuyó el periodo presidencial de 7 a 5 años. Ello impide que las autoridades electivas se alejen de la voluntad efectiva del cuerpo político de la sociedad y se mantengan atentos a la solución de los temas políticos, económicos y sociales más relevantes para la ciudadanía. 
te a través de su voto, ya que no existe la perspectiva de la concentración unipersonal del poder ejecutivo que se da en el presidencialismo. En tal perspectiva, debe modificarse a tal efecto el inciso $2^{\circ}$ del artículo 25 de la Constitución, para posibilitar el aumento del periodo presidencial en el caso que se opte por aumentarlo a cinco años, como asimismo, para posibilitar la reelección inmediata por una sola vez.

Es adecuado mantener las elecciones simultáneas de Presidente de la República y de Congreso Nacional uni o bicameral, lo que potencia la posible concordancia de la mayoría presidencial con la mayoría parlamentaria, favoreciendo la votación en bloque del elector, siendo recomendable que la elección parlamentaria se realice junto con la eventual segunda votación de la elección presidencial si ningún candidato presidencial ha obtenido la mayoría absoluta en la primera votación.

El sistema no garantiza una mayoría parlamentaria para el Presidente de la República, ya que la ciudadanía puede preferir un gobierno dividido, votando para parlamentario por un partido diferente de la opción presidencial, de manera tal que una mayoría parlamentaria heterogénea obliga a establecer un gobierno de cooperación y coalición que puede ser considerado más satisfactorio para el cuerpo político de la sociedad.

Por otra parte, la facultad presidencial de disolver el parlamento o la cámara baja del mismo (en caso de mantener un bicameralismo), genera igualmente la hipótesis de elecciones separadas de Presidente de la República y de Congreso.

\subsection{Consideraciones sobre el método electoral para elegir Presidente de la República y parlamento}

En tal sentido, es necesario tener presente que esta perspectiva requiere de fórmulas electorales que no sean restrictivas del pluralismo político existente en la respectiva sociedad política, posibilitando una relación directa entre las preferencias ciudadanas y su reflejo en las decisiones institucionales. El sistema electoral debiera revelar con autenticidad las preferencias de los votantes.

El sistema electoral debe ser adecuado a la realidad de elección separada del Presidente de la República y de Congreso Nacional, pronunciándose sobre la simultaneidad o secuencia temporal de la elección presidencial y parlamentaria.

El Presidente de la República debe ser elegido por la mayoría efectiva del cuerpo electoral, lo cual lo dota de la legitimidad democrática para ejercer sus funciones constitucionales. El sistema electoral parlamentario no debiera producir una práctica de gobierno presidencial, si este no cuenta con una mayoría parlamentaria que sea expresión fiel y mayoritaria del cuerpo político de la sociedad.

Esta perspectiva desecha la utilización de sistemas mayoritarios uninominales de mayoría relativa, ya que esta crea mayorías parlamentarias artificiales que no corresponden a la voluntad real de la ciudadanía. Asimismo, este sistema es aconsejable para la elección presidencial, ya que posibilita presidentes de doble minoría nefastos para el desarrollo institucional democrático y para procesar las demandas sociales, por 
ser gobiernos que representan sólo una minoría del cuerpo electoral y generalmente son también mino ritarios en el apoyo parlamentario, lo que genera un caldo de cultivo para el bloqueo institucional y la parálisis y crisis del sistema institucional. La situación es aún peor si el Presidente con doble minoría, electoral y parlamentaria se ubica en un extremo del espectro político e ideológico existente en la sociedad política, ya que ello agudiza el descontento social, la insatisfacción de las necesidades urgentes de la población y genera la posibilidad de crisis del sistema institucional.

\subsubsection{Elección presidencial por sistema mayoritario uninominal a dos vueltas}

Un presidente que ejerce funciones políticas reales requiere una legitimidad democrática fuerte que solo está dada por su elección por la mayoría absoluta del cuerpo electoral, lo que significa elección por un sistema mayoritario uninominal a dos vueltas, donde si en la primera votación no obtiene el respaldo de mayoría absoluta uno de los candidatos se produce una segunda votación sólo entre los dos candidatos que hayan obtenido el mayor número de preferencias en la primera votación. El sistema se encuentra actualmente vigente en los dos regímenes semipresidenciales con mayor trayectoria histórica como son Francia y Finlandia, como asimismo en Portugal; Polonia y Rumania.

El sistema ya se encuentra institucionalizado en una parte en los presidencialismos latinoamericanos como Brasil, Chile, Colombia, República Dominicana, Guatemala, Perú, Uruguay y Venezuela.

En tal sentido, proponemos mantener las disposiciones contenidas sobre sistema electoral presidencial en el artículo 26 de la Constitución.

En la perspectiva semipresidencial, la elección del Presidente de la República en sistema mayoritario a doble vuelta tiende a producir un alineamiento bipolar, y un multipartidismo más o menos moderado, ya que en la primera votación se miden las fuerzas de cada partido o coalición y en la segunda se escoge al de su preferencia si está entre los dos primeros y el resto de la ciudadanía escoge al que considera más cercano a sus opciones o mal menor, salvo que entren en una coalición entre primera y segunda vuelta, donde hay espacio para la negociación política y la concertación de acuerdos de gobierno.

El alineamiento bipolar para la segunda votación de la elección presidencial influye significativamente en la elección parlamentaria si esta se desarrolla junto con la segunda votación presidencial. En tal sentido, sería conveniente que la elección parlamentaria se realizara junto con la segunda vuelta presidencial o treinta días después de la elección presidencial si el Presidente es elegido en primera votación, lo que requiere ajustar a tal perspectiva el artículo 26 inciso $1^{\circ}$ de la Constitución.

\subsection{Requisitos de elegibilidad, sistema calificación elección presidencial y sistema de reemplazo del Presidente electo o en ejercicio}

En esta perspectiva, debiera mantenerse los requisitos de elegibilidad previsto en la Constitución Política en los artículos 25 y 26 vigentes. A simismo puede mantenerse 
el sistema de calificación de la elección presidencial previsto en el artículo 27, como el sistema de reemplazo del Presidente electo por impedimento temporal o absoluto del artículo 28 de la Constitución.

Respecto de reemplazo del Presidente de la República en ejercicio debe subrogarlo el Presidente del Senado en caso de mantenerse el bicameralismo o el Presidente de la Cámara de Diputados en caso de unicameralismo, y a falta de estos últimos, por el Presidente de la Corte Suprema de Justicia, debiendo modificarse en tal sentido el artículo 29 inciso $1^{\circ}$ de la Constitución.

En caso de vacancia presidencial, el Vicepresidente, dentro de los diez primeros días de su mandato deberá convocar a elección presidencial para el sexagésimo día después de la convocatoria. El Presidente que resulte elegido asumirá el cargo por un periodo presidencial completo, lo que requiere sustituir los incisos $2^{\circ}$ a $5^{\circ}$ del artículo 29 .

A simismo, debe agregarse un inciso nuevo al artículo 29 que establezca que "EI Vicepresidente de la República tendrá todas las atribuciones que esta Constitución confiere al Presidente de la República", eliminándose el actual artículo 31 de la Constitución.

A simismo, debe mantenerse el actual artículo 30 referente al cese de las funciones presidenciales y el estatuto de ex Presidente de la República. En este último aspecto, nos parece adecuado mantener la renta fijada por el artículo 62 de la Constitución, pero nos parece poco republicano y afecta la igualdad de todos los ciudadanos que un ex Presidente de la República cuente con fuero especial penal, el cual se justificó coyunturalmente por el caso Pinochet, pero que no tiene fundamento en una República Democrática, por lo cual se sugiere eliminar en el artículo 30 las referencias a los incisos $2^{\circ}, 3^{\circ}$ y $4^{\circ}$ del artículo 61 de la Constitución.

\section{DISTRIBUCIÓN DE FUNCIONES Y ATRIBUCIONES ENTRE EL PRESIDENTE DE LA REPÚBLICA Y EL GOBIERNO DIRIGIDO POR EL PRIMER M INISTRO}

Establecer un tipo de gobierno semipresidencial implica distribuir de manera diferente las funciones y atribuciones que hoy detenta el Presidente de la República, distinguiendo entre atribuciones presidenciales que pueden ejercerse sin o con refrendo gubernamental y atribuciones que ejerce el Primer M inistro como Jefe de Gobierno.

\subsection{Las funciones y atribuciones del Presidente de la República}

En el régimen semipresidencial el Presidente de la República es Jefe de Estado, Jefe Supremo de las Fuerzas A rmadas, vela por el respeto de la Constitución y asegura, por su arbitraje, el funcionamiento regular de los poderes públicos. El Presidente de la República garantiza la independencia nacional, la integridad del territorio y el respeto de los principios generales del derecho internacional y los tratados internacionales. 
Desde esta perspectiva, debe modificarse el artículo 24 de la Constitución, considerando en el mismo las funciones generales del Presidente de la República antes mencionadas.

Asimismo, debe modificarse el artículo 32 de la Constitución Política, el cual debe distinguir las atribuciones presidenciales ejercidas sin y con refrendo del Primer Ministro.

\subsection{Las atribuciones del Presidente de la República}

Las atribuciones del Presidente de la República pueden clasificarse en atribuciones sin refrendo del Primer Ministro, atribuciones que requieren iniciativa o acuerdo de otro órgano constitucional y atribuciones que requieren refrendo del Primer M inistro.

4.2.1. A tribuciones que no requieren refrendo del Primer M inistro y atribuciones que requieren iniciativa o acuerdo de otro órgano constitucional.

En una cierta aproximación, podemos señalar que el Presidente de la República podría disponer de las siguientes atribuciones, las que debiera ejercer sin refrendo ministerial.

Así, el artículo 32 nuevo de la Carta Fundamental debiera establecer:

"Son atribuciones especiales del Presidente de la República:

1) Nombrar al Primer Ministro previa consulta con los líderes de los diferentes partidos políticos con representación en la Cámara de Diputados.

2) Disolver la Cámara de Diputados, convocando inmediatamente a elecciones parlamentarias que se realizarán en un plazo no inferior a 60 ni mayor de 90 días, para hacer frente a un conflicto político grave de esta con el gobierno o en caso de una cuestión nacional de importancia excepcional.

3) Convocar a plebiscito o referéndum en los casos expresamente señalados en la Constitución.

4) Dirigir mensajes al Parlamento o a la ciudadanía.

5) Convocar al Consejo de Ministros bajo su presidencia.

6) Ejercer iniciativa de reforma constitucional.

7) Ejercer el derecho de veto suspensivo sobre proyectos de ley, antes de su promulgación;

8) Promulgar las leyes y ordenar su publicación en el Diario Oficial.

9) Ejercer legitimación activa ante el Tribunal Constitucional para activar el control de constitucionalidad en forma preventiva o reparadora respecto de preceptos legales, normas administrativas, reglamentos parlamentarios, autos acordados de tribunales superiores de justicia o de tribunales especiales que considere inconstitucionales.

10) Representar al Estado en el exterior, acreditar a los embajadores y ministros extraordinarios ante las potencias extranjeras u organismos internacionales. Los embajadores, enviados extraordinarios y cónsules de otras potencias se acreditan ante el Presidente de la República.

11) Conducir las relaciones políticas con las potencias extranjeras y organismos 
internacionales. Las decisiones de política internacional deben se adoptadas en Consejo de M inistros.

12) Designar y remover a los comandantes en jefes de las ramas de las Fuerzas A rmadas y al General Director de Carabineros en conformidad con la Constitución; y disponer el nombramiento, ascenso y retiro de los oficiales de las Fuerzas A rmadas y Carabineros en la forma establecida por la Constitución y las leyes.

13) Presidir los consejos y comités superiores de la defensa y seguridad nacional.

14) Disponer de las fuerzas de aire, mar y tierra, organizarlas y distribuirlas, según las necesidades del país.

15) Declarar la guerra, previa autorización por ley, debiendo dejar constancia de haber oído al Consejo de Seguridad Nacional;

16) Nombrar tres M inistros del Tribunal Constitucional;

17) Velar por la conducta ministerial de los jueces y demás empleados del poder judicial y requerir, con tal objeto, a la Corte Suprema para que, si procede, declare su mal comportamiento, al ministerio público, para que reclame medidas disciplinarias del tribunal competente, o para que, si hubiere mérito bastante, entable la correspondiente acusación;

18) Otorgar indultos particulares en los casos y formas que determine la ley. El indulto será improcedente en tanto no se haya dictado sentencia ejecutoriada en el respectivo proceso. Los funcionarios acusados por la Cámara de diputados y condenados por el Senado, solo pueden ser indultados por el Congreso;

19) Disponer de la potestad administrativa para organizar la estructura y funcionamiento de los servicios públicos dependientes de la Presidencia de la República.

20) Nombrar y remover a los funcionarios que la ley determine como de su exclusiva confianza.

21) Nombrar al Contralor General de la República con acuerdo de la mayoría de los senadores en ejercicio (o cámara única).

22) Nombrar a los Ministros de la Corte Suprema de Justicia de entre aquellos propuestos en lista de cinco nombres por la Corte Suprema de Justicia con acuerdo de los tres quintos de los senadores en ejercicio (o cámara única, en su caso), y al Fiscal Nacional, a proposición de la Corte Suprema y con el acuerdo del Senado. Nombrar a los magistrados y fiscales judiciales de las Cortes de apelaciones y los jueces letrados, a proposición de la Corte Suprema y de las Cortes de A pelaciones respectivamente.

En el ámbito político, en régimen semipresidencial, el Presidente de la República debe contar con la iniciativa para nombrar al Primer M inistro.

Hipótesis 1: el Primer M inistro o Jefe de Gobierno será un hombre de confianza del Presidente de la República, si este último es el líder de una mayoría parlamentaria unipartidista o con un partido hegemónico, operando el Primer Ministro como su jefe de estado mayor, siendo un fusible que puede ser reemplazado en casos de crisis política.

Hipótesis 2: El Primer Ministro será el líder de uno de los partidos de la coalición de gobierno distinto al del Presidente de la República, si se requiere mantener una alianza con partidos de fuerza eventualmente equilibrada, lo que otorga una capacidad de 
autonomía relativa al Primer Ministro respecto del Presidente de la República, la que será limitada. En esta hipótesis también puede utilizarse al Primer Ministro como un fusible que se reemplaza para superar crisis al interior de la mayoría gubernamental.

Hipótesis 3: El Primer Ministro será el jefe de la oposición parlamentaria al Presidente de la República, si este último se encuentra en minoría en el parlamento, dando lugar a un proceso de cohabitación como ha sido denominado en Francia, donde ha operado tanto con un Presidente Socialista y un gobierno de centro derecha y viceversa, como también ha operado en Portugal en la década de los ochenta y noventa del siglo XX. En esta hipótesis "el presidencialismo es neutralizado y cede el puesto al gubernamentalismo". ${ }^{11}$

El Presidente de la República cuenta políticamente con un arma significativa como es la disolución parlamentaria, como atribución privativa, la cual le permite eventualmente intentar un cambio de mayoría parlamentaria y generar un gobierno unificado si el Presidente tiene éxito, de lo contrario, éste deberá quedarse con un ejercicio estricto de su competencias constitucionales y dejar gobernar a un Primer Ministro con un programa de gobierno diferente al suyo sustentado en el respaldo de la mayoría parlamentaria, por lo menos hasta el siguiente proceso electoral.

El Presidente puede dirigir mensajes al Congreso y a la ciudadanía con lo cual puede hacer presente a uno u otro su perspectiva sobre determinados temas de relevancia nacional, proyectos de reforma constitucional, razones para disolver la Cámara de Diputados o para convocar a referéndum o plebiscito en casos que determine la Constitución.

El derecho de veto suspensivo sobre proyectos de ley y reforma constitucional le permite bloquear las iniciativas en las cuales el Presidente de la República se encuentra en desacuerdo, veto que puede ser superado en los casos de proyectos de ley por la mayoría de los diputados en ejercicio y, en el caso de reformas constitucionales por la mayoría de tres quintos de los diputados en ejercicio.

El Presidente nombra una parte de los magistrados del Tribunal Constitucional y, a su vez, puede requerir en control preventivo de constitucionalidad proyectos de reformas constitucionales, proyectos de ley, o en control represivo proyectos de ley o normas administrativas ante el Tribunal Constitucional.

En las atribuciones establecidas en los numerales 20, 21 y 22, si bien el Presidente de la República no requiere de refrendo del Primer M inistro, si requiere la proposición o el acuerdo de otro órgano constitucional.

Consideramos conveniente dejar sentado que es necesario establecer una carrera judicial sólo hasta Ministro de Corte de A pelaciones. Debiera abrirse el acceso a la

11 Charlot, Jean. La politique en France. Éditions de Fallois, Paris, 1994, p.188. 
Corte Suprema por concurso público y debiera acotarse el mandato a 9 años como ocurre en el caso de Tribunal Constitucional. Asimismo, debiera establecerse un órgano de gobierno del Poder Judicial.

En materia de adopción de decisiones en materia de política internacional que desea adoptar el Presidente de la República, debe hacerlo en Consejo de Ministros, lo cual obliga al Presidente a escuchar al Primer Ministro y Ministros de Estado, aun cuando ellas no sean vinculantes para el Presidente.

\subsubsection{A tribuciones presidenciales sujetas a refrendo del Primer Ministro}

En el ámbito de estas atribuciones se expresa la solidaridad real y la existencia de una decisión compartida que existe entre el Presidente de la República y el Primer $M$ inistro en estas materias, donde la firma del Primer M inistro pone eventualmente en causa su responsabilidad política ante la Cámara de Diputados.

a) Declarar o prorrogar los estados de excepción nacional expresamente consignados en la Constitución, en los casos y formas prevista por ella.

b) Declarar la guerra, previa autorización por ley.

c) Nombrar los M inistros de Estado.

d) Nombrar a los embajadores y ministros diplomáticos, y a los representantes ante organismos internacionales o supranacionales, así como su remoción de sus funciones.

e) Los reglamentos y decretos emitidos en Consejo de Ministros.

\subsection{Responsabilidad Política del Presidente de la República}

Este es un punto que no puede dejar de considerarse en un régimen semipresidencial, ya que el Presidente de la República ejerce atribuciones que no son refrendadas por el Primer M inistro, lo que exige al Jefe de Estado hacerse responsable políticamente de ellas. En esta perspectiva nos parece adecuado considerar la competencia de la Cámara de Diputados para poder convocar a un referéndum o plebiscito por la mayoría calificada de $3 / 5$ de sus miembros en ejercicio, en el cual se ponga en juego la responsabilidad política del Presidente de la República, el cual será revocado de sus funciones si en el plebiscito o referéndum vota más del $50 \%$ del cuerpo electoral y la votación por la revocatoria constituye la mayoría absoluta de los votos válidamente emitidos.

Este mecanismo permite el equilibrio de la facultad de disolución del parlamento por parte del Presidente de la República y evita bloqueos institucionales.

Debe establecerse así una nueva disposición constitucional entre las atribuciones exclusivas de la Cámara de Diputados, en el artículo 52: “Convocar a plebiscito por la mayoría de tres quintos de los diputados en ejercicio para que la ciudadanía se pronuncie sobre la revocación de sus funciones del Presidente de la República en ejercicio. El Presidente de la República cesará de inmediato sus funciones, cuando en dicho plebiscito la mayoría absoluta de los sufragios válidamente emitidos se haya pronun- 
ciado a favor de la revocatoria, habiendo concurrido al acto electoral más del $50 \%$ del cuerpo electoral".

\section{EL GOBIERNO Y SUS ATRIBUCIONES}

En el tipo de gobierno semipresidencial siempre será el Primer Ministro quien determina y dirige la política gubernamental.

El gobierno es el que desarrolla el programa de gobierno, ya sea como expresión unificada de las orientaciones determinadas por el Presidente respaldado por la mayoría parlamentaria, o como expresión autónoma del gobierno sustentado y respaldado por la mayoría parlamentaria.

El Primer M inistro o Jefe de Gobierno es nombrado por el Presidente de la República, quien nombra también a los ministros de Estado a propuesta del primero.

El Primer M inistro y los Ministros de Estado están vinculados por el programa de gobierno y los acuerdos adoptados en Consejo de Gabinete.

El Primer Ministro y su gabinete se someten con su programa de gobierno a la consideración de la Cámara de Diputados, dentro del plazo de treinta días desde el nombramiento del primero, dicho voto de investidura debe contar con el apoyo de la mayoría de los diputados en ejercicio.

El Primer M inistro es responsable políticamente ante la Cámara de Diputados.

Los ministros de Estado son responsables políticamente en el ámbito de sus competencias ante el Primer M inistro, quien puede solicitar al Presidente de la República la remoción de sus funciones.

El Primer M inistro preside el Consejo de Gabinete, integrado por todos los M inistros de Estado.

Son atribuciones del Primer Ministro:

a) Elaborar y proponer a la Cámara de Diputados el programa de gobierno, el que debe ser aprobado por la mayoría de los diputados en ejercicio.

b) Proponer al Presidente de la República el nombramiento de Ministros de Estado y su remoción.

c) Solicitar a la Cámara de Diputados un voto de confianza sobre una declaración de política general o sobre todo asunto relevante de importancia nacional.

d) Proponer al Presidente de la República, previa deliberación en Consejo de Gabinete, la disolución de la Cámara de Diputados. Dicha proposición no podrá ser realizada ni deliberada cuando se haya presentado una moción de censura y esta se encuentre en trámite o cuando se encuentre vigente un Estado de Excepción Constitucional. 
e) Ejercer la iniciativa de ley o la iniciativa exclusiva de ley en los casos previstos en la Constitución.

f) Concurrir a la formación de las leyes de conformidad con la Constitución (participación de Ministros en el debate de las leyes en Sala y Comisión; determinación de urgencia; derecho de veto suspensivo en materia de ley y reformas constitucionales, entre otros aspectos).

g) Ejercer la potestad reglamentaria autónoma o de ejecución de las leyes.

h) Nombrar a los jefes superiores de los servicios públicos y los demás funcionarios que se consideren de exclusiva confianza de acuerdo con la ley y removerlos.

i) Proveer los demás empleos públicos de acuerdo con la Constitución y la ley.

j) Conceder jubilaciones, retiros y goce de montepío con arreglo a las leyes.

k) Requerir el pronunciamiento del Tribunal Constitucional acerca de la constitucionalidad de reformas constitucionales, preceptos legales, administrativos u otros que determine la Constitución o las leyes.

I) Cuidar de la recaudación de las rentas públicas y decretar su inversión de acuerdo a la ley. El Primer Ministro con la firma de todos los M inistros de Estado, podrá decretar pagos no autorizad os por ley, sólo para atender necesidades impostergables derivadas de calamidades públicas, de guerra, de conmoción interna o del agotamiento de los recursos destinados a mantener servicios que no pueden paralizarse sin grave daño para el país. El total de los giros que se hagan con estos efectos, no podrá exceder anualmente de dos por ciento $(2 \%)$ del monto de los gastos que autorice la ley general de presupuestos. Se podrá contratar empleados con cargo a esta misma ley, pero sin que el ítem respectivo pueda ser incrementado o disminuido mediante traspasos. Los M inistros de Estado o funcionarios que autoricen o den curso a gastos que contravengan lo dispuesto en este número, serán responsables solidaria y personalmente de su reintegro y culpables del delito de malversación de caudales públicos.

m) Ejercer las demás atribuciones que le otorguen la Constitución o las leyes.

El gobierno cesa en funciones cuando no logra el voto de investidura en la Cámara de Diputados; cuando es removido el Primer M inistro por el Presidente de la República; cuando es aprobado un voto de desconfianza constructivo por la Cámara de Diputados; o cuando el Primer M inistro renuncia, muere o se declara su incapacidad absoluta, previo dictamen del Tribunal Constitucional.

El gobierno dimisionario permanece en funciones hasta la toma de posesión de un nuevo Primer Ministro, desarrollando las funciones administrativas corrientes.

Cualquiera sea la decisión final, si mantener el presidencialismo o cambiarlo, el Estado chileno necesita un servicio civil técnica y profesionalmente competente, del cual se carece actualmente. La mayoría de los escándalos investigados tienen como causa funcionarios de bajo nivel de competencia para el cargo que ocupan, mal remunerados y actuando como operadores políticos para sus respectivos partidos. El país necesita un servicio civil competente, calificado, eficiente, independiente del gobierno de turno. Esta es una tarea impostergable. 


\subsection{Relaciones del gobierno con la Cámara de Diputados o el Congreso unicameral}

Como ya hemos señalado somos partidarios de un parlamento unicameral y en caso de bicameralismo, la segunda cámara (Senado), debe tener competencia solo en materia legislativa y de nombramiento de autoridades de órganos constitucionales (Corte Suprema; Fiscal Nacional; Contraloría General de la República, entre otros). El Senado no debe fiscalizar al gobierno y no debe intervenir en las relaciones políticas Gobierno-Parlamento.

Son atribuciones exclusivas de la Cámara de Diputados:

1. Otorgar o denegar la confianza política solicitada por el Primer M inistro.

2. Hacer efectiva la responsabilidad política del Primer M inistro y su gabinete, mediante la aprobación de un voto de censura constructivo.

3. Formular interpelaciones al Primer M inistro y a los M inistros de Estado.

4. Fiscalizar los actos de gobierno.

5. A probar por la mayoría de tres quintos de los diputados en ejercicio la convocación a un referéndum, para que la ciudadanía se pronuncie sobre la continuidad o la pérdida del mandato del Presidente de la República. Dicha convocación se puede realizar sólo una vez durante el periodo parlamentario.

El Primer Ministro debe concurrir dentro de los treinta días siguientes a su nombramiento por parte del Presidente de la República ante la Cámara de Diputados para exponer, debatir y obtener la aprobación del programa de gobierno y las principales medidas políticas y legislativas que requiere su gestión, programa que debe ser aprobado por la mayoría de los diputados en ejercicio. Esta perspectiva implica que el Presidente de la República no puede imponer un Primer M inistro que no cuente con el respaldo de la mayoría parlamentaria.

El Primer M inistro puede comprometer la responsabilidad política del gobierno en la aprobación de un determinado proyecto de ley, lo que implica que de no ser aprobado el proyecto el gobierno debe presentar su dimisión ante el Presidente de la República.

La Cámara de Diputados puede hacer efectivo un voto de desconfianza constructivo respecto del gobierno, el que podrá ser presentado a iniciativa de una quinta parte de los diputados en ejercicio, el cual contendrá el nombre del candidato a Primer Ministro y un programa de gobierno alternativo, así de ser aprobado el voto de desconfianza constructivo asumirá como nuevo Primer Ministro el propuesto y votado por la Cámara de Diputados. Dicho voto que es de censura e investidura simultáneamente, debe ser aprobado por la mayoría de los diputados en ejercicio.

La aprobación del voto de desconfianza constructivo implica la cesación inmediata del gobierno censurado y el nombramiento del nuevo gobierno aprobado por la Cámara de Diputados por el Presidente de la República. 
El voto de desconfianza constructivo si bien conspira con la libertad de maniobra del Presidente de la República para conformar un gobierno de mayoría relativa, contribuye a otorgar estabilidad a los gobiernos y evita las rotativas ministeriales que son contrarias a una adecuada gobernabilidad democrática del sistema político.

A su vez, una quinta parte de los diputados en ejercicio debiera estar facultada para interpelar a los ministros de Estado o al Primer Ministro, la que debe formularse por escrito y los interpelados debieran contestar las interpelaciones que se le hayan hecho llegar con 72 horas de anticipación en una sesión especial los días viernes de cada semana. La respuesta de las interpelaciones dan derecho a réplica de los diputados que hayan presentado la interpelación y derecho a dúplica del ministro interpelado.

Asimismo, la facultad del Presidente de la República de disolver la Cámara de Diputados no puede ser ejercida mientras se tramita un voto de censura contra el gobierno, durante un Estado de Excepción Constitucional o en el último año del mandato presidencial.

Con el objeto de evitar la perspectiva posible de un Presidente de la República minoritario en la voluntad popular y en el parlamento producto de su desgaste o mala gestión, el cual obstruya el proceso político o pueda intentar provocar una crisis del sistema institucional, debe establecerse la posibilidad de su destitución del cargo a través de un referéndum, luego de un procedimiento en el cual la Cámara de Diputados adopta el acuerdo de convocar al referéndum por tres quintos de los diputados en ejercicio, adoptada dicha decisión, el Presidente queda suspendido de sus funciones, las cuales son asumidas por el Vicepresidente de la República. Si el referéndum se pronuncia a favor de la destitución del Presidente de la República, este cesara en el cargo. Por el contrario, si el Presidente es ratificado en el cargo por la confianza ciudadana, este reasume sus funciones y disuelve la Cámara de Diputados llamando de inmediato a una nueva elección parlamentaria. Para que dicho plebiscito sea válido debe concurrir más del cincuenta por ciento de los ciudadanos inscritos en los registros electorales. La destitución del Presidente en dicho plebiscito sólo se realizará si los votos en contra del Presidente de la República constituyen más del $50 \%$ de los votos emitidos por los ciudadanos.

La atribución de convocar a referéndum para determinar la eventual destitución del Presidente de la República, lo podrá ejercer la Cámara de Diputados una sola vez durante el respectivo periodo legislativo.

\section{SISTEM A ELECTORAL PARA CONGRESO NACIONAL: ELECCIÓN DEL PARLA MENTO POR SISTEM A PROPORCIONAL PERSONALIZADO}

En tal sentido, consideramos que la alternativa que ofrece más satisfacciones a la ciudadanía y explicita mejor la representatividad, potenciando la tendencia a la colaboración y al compromiso se encuentra en el ámbito de la representación proporcio- 
nal, el que no margina del sistema institucional de decisiones políticas a los partidos políticos significativos y representativos de un sector de la ciudadanía.

No es aconsejable sistemas mayoritarios uninominales, que dejan a sectores importantes de la ciudadanía sin representación política, generándose mayorías artificialmente construidas que no corresponden a la voluntad real del cuerpo político de la sociedad.

Chile tiene un sistema de multipartidismo estructurado que responde a realidades de clivages históricos, culturales, y socioeconómicos, el que no ha variado significativamente en el último medio siglo, hoy tenemos siete partidos políticos con más de un $5 \%$ de los votos, lo que no es diferente de la realidad de los años 60 y 70 del siglo XX.

El multipartidismo chileno se ha mantenido pese al sistema binominal: dos partidos de derecha UDI y RN; cuatro partidos en la concertación DC, PS, PPD y PR, y el Partido Comunista.

\section{El sistema electoral debe reconocer esta realidad y asumirla.}

Dentro de la representación proporcional nos inclinamos por distritos medianos de 5 a 7 escaños con método D'Hont o método de la igualación (Udda o Sainte Lague) o alternativamente por un sistema de representación proporcional personalizado como el existente en A lemania Federal, en el cual se combinan distritos uninominales con un segundo voto por listas cerradas bloqueadas presentadas por los partidos políticos, en que la proporción de este segundo voto de lista del ciudadano, es el que determina la representación de cada fuerza política en el parlamento, ya que los cargos de lista se atribuyen a los partidos descontando los cargos obtenidos directamente del voto ciudadano en las circunscripciones uninominales, de manera que cada partido tiene una representación fidedigna en el parlamento, ampliamente representativa de la voluntad ciudadana.

El sistema electoral proporcional personalizado otorga a cada fuerza electoral la cuota de representación que corresponde a sus votos y al apoyo ciudadano, pero los parlamentarios obtenidos emanan en parte de la decisión directa del elector por el parlamentario en los distritos uninominales y de su preferencia ideológico programática en el segundo voto por lista de partidos, posibilitando una mayor cercanía con los electores y una rendición más efectiva de cuenta de los parlamentarios.

En el contexto actual chileno, un régimen semipresidencial no puede funcionar con un sistema electoral parlamentario como el binominal, el cual no ha impedido que existan al menos seis partidos políticos con representación parlamentaria en todo el periodo (UDI, Renovación Nacional, Democracia Cristiana, Partido Socialista, Partido por la Democracia y Partido Radical social demócrata) en un esquema bipolarizado, marginando del sistema institucional a fuerzas políticas con más del $5 \%$ de los votos válidamente emitidos (Partido Comunista). 
El sistema impide la representación de las demás fuerzas políticas que no pertenecen a los dos bloques o pactos más importantes, lo que implica que estas fuerzas se expresan extra parlamentariamente. Ello hace que los partidos se aglutinen en dos pactos electorales con pluralidad de fuerzas políticas, la Alianza por Chile (derecha) y la Concertación de Partidos por la Democracia. El Partido Comunista u otra fuerza política en este esquema no tiene posibilidades de obtener parlamentarios salvo que tenga mayoría en un distrito o circunscripción específico, lo que no ha ocurrido en todo el periodo analizado.

Es un sistema que tiende a la bipolarización en dos alianzas electorales fuertes. ${ }^{12}$ Una de sus fortalezas son los incentivos a la gobernabilidad, ya que la elección presidencial marca las alianzas en las elecciones parlamentarias, donde los partidos se unen en pos de la posibilidad de acceder al gobierno. Los estímulos para la formación de coaliciones han aumentado en comparación al Chile pre-autoritario. Es innegable que la A lianza por Chile (derecha) y la Concertación (centro izquierda) son las coaliciones más largas y perdurables de la historia contemporánea chilena dentro de gobiernos presidencialistas.

El estímulo a la gobernabilidad y la política de coaliciones en pos de obtener el gobierno se da en régimen semipresidencial sin necesidad de binominalismo, ya que ninguna fuerza política por sí sola puede alcanzar el gobierno.

Una de las debilidades del binominalismo consiste en que tiene poca representatividad para lograr la distribución de escaños en el Congreso, en la medida que impide la obtención de mandatos por las terceras y siguientes fuerzas políticas, que no pertenecen a una de las dos alianzas electorales principales.

La ausencia de competencia entre las listas debilita el significado y la relevancia del voto de los ciudadanos. A su vez, se ha llegado incluso a que una coalición lleve un solo candidato, con lo cual está prácticamente elegido antes que los ciudadanos voten en la elección.

Los líderes de los partidos están forzados a comprometerse en elaboradas y agotadoras negociaciones para reunir listas de dos candidatos en los 60 distritos electorales del país. Los partidos fuertes deben considerar necesariamente las demandas de los partidos pequeños, porque sus votos son necesarios en las elecciones presidenciales, contribuyen en algunos casos a posibilitar la existencia de doblajes en algunos distritos y permiten mantener la coalición. Las negociaciones entre los partidos implican en algunos casos ceder algunos asientos en la Cámara de Diputados a cambio de candidaturas senatoriales o viceversa. Los partidos fuertes de los subpactos de la Concerta-

12 NAVIA, Patricio y Cabezas, José Miguel. Efecto del sistema binominal en el número de candidatos y de partidos en elecciones legislativas en Chile, 1989-2001. Vol. 45 (primavera), pp. 29-52, 2005. GuZMÁN, Eugenio. "Reflexiones sobre el sistema binominal", Revista Estudios Públicos 51 (invierno), 1993. pp. 303-324. 
ción usan asimismo las encuestas de opinión pública y los resultados previos para dividir equitativamente las candidaturas a lo largo del país.

A su vez, los partidos conocen su porcentaje de votación aproximadamente, por lo que las directivas partidarias negocian intra coalición o pacto, las candidaturas, llevando candidatos fuertes que serán elegidos y candidatos débiles que sirven solo de acompañamiento, lo que hace que el ciudadano sólo decide la orientación general por la que desea votar pero no tiene ninguna influencia en quienes son los candidatos que se elegirán, los que ya están predeterminados, todo lo cual desincentiva la participación ciudadana en las elecciones. Hoy el $48 \%$ de los ciudadanos no participa del proceso electoral. Hoy hay 2.500.000 jóvenes no inscritos en el registro electoral.

Para superar dicha situación, en una perspectiva de compromiso, sugiero sin que ello sea un ideal, que podría pensarse en sumarse 30 diputados y 12 senadores a los actualmente existentes, todos elegidos en lista cerrada bloqueada nacional, utilizando el cociente Udda o Sainte Lagüe, o la cifra repartidora (sistema D'Hondt) que determina este segundo voto de lista del ciudadano, siendo este segundo voto el que precisa la representación de cada fuerza política en el parlamento, ya que los cargos de lista se atribuyen a los partidos descontando los cargos obtenidos directamente del voto ciudadano en las circunscripciones binominales, de manera que cada partido tenga una representación fidedigna en el parlamento, representativa de la voluntad ciudadana. Un partido podría tener mandatos de sobrerrepresentación si en los votos de lista no alcanza a obtener el número de diputados obtenidos directamente en los distritos binominales.

Esta perspectiva debería complementarse con una barrera o umbral de representación que imposibilitara la representación parlamentaria de partidos con menos del 3 ó $4 \%$ de los sufragios nacionales válidamente emitidos de acuerdo con el segundo voto de lista.

\section{CONSIDERACIONES FINALES SOBRE TIPO DE GOBIERNO SEMIPRESIDENCIAL}

El régimen semipresidencial ofrece innegables ventajas funcionales frente al presidencialismo latinoamericano, como hemos demostrado, manteniendo una separación flexible de poderes y un ejecutivo dual que mantiene la figura institucional del Presidente de la República enraizada culturalmente en dos siglos de evolución latinoamericana, con poderes reales pero limitados, dentro de un régimen constitucional democrático equilibrado y con controles políticos y jurídicos efectivos, como asimismo con arbitrajes del cuerpo político de la sociedad que permiten solucionar dentro del sistema democrático constitucional todos los posibles bloqueos políticos institucionales, manteniendo un nivel de gobernabilidad satisfactorio.

En este sentido la gobernabilidad solo es posible si el desempeño de la función gubernamental posibilita la adopción de decisiones oportunas ante las demandas efectuadas por los diversos sectores de la sociedad; tales decisiones tienen en el sistema semipresidencial mayores posibilidades de producir satisfacción social, además de 
preservar una cierta coherencia en el tiempo. ${ }^{13}$ Finalmente esta gobernabilidad democrática dentro de un sistema semipresidencial exige que las instituciones gubernamentales cuenten con suficiente legitimidad y respaldo social y político.

El sistema semipresidencial a diferencia del presidencialismo opera en base a la cooperación entre los diversos actores políticos e institucionales, en base a consensos mayoritarios y no a la imposición de un Presidente de la República, desgastado y muchas veces en confrontación abierta con el Congreso Nacional. En el semipresidencialismo no hay cabida para mesianismos presidenciales por sus mecanismos de control político y jurídico, que permiten tener conciencia a los jefes de Estado de sus poderes limitados.

El semipresidencialismo contribuye funcionalmente también a disciplinar a los parlamentarios de gobierno, ya que en la votación de cada proyecto, no solo deben tener en consideración los fundamentos del proyecto en sí mismo, sino también tener presente que se juega el sostenimiento del gobierno en curso.

\subsection{Descentralización territorial y gobiernos regionales}

En esta materia, es necesario avanzar hacia una real regionalización y descentralización regional dentro del marco de un Estado Unitario. Debemos pasar de regiones objeto de desarrollo bajo control del gobierno central, a regiones sujeto de su propio desarrollo, lo que requiere que los órganos colegiado normativo, resolutivo y fiscalizador, como la autoridad unipersonal que sea ejecutivo del gobierno regional sean representativas de la ciudadanía regional.

En tal perspectiva deben ser elegidos directamente por la ciudadanía los consejeros regionales, el sistema actual se encuentra agotado y no es sostenible en el tiempo, es hora de reemplazarlo.

En el ámbito del ejecutivo del gobierno regional, éste no puede continuar en manos del Intendente, quien debe mantenerse sólo como órgano de gobierno interior, manteniéndose el sistema de nombramiento actual.

El ejecutivo del gobierno regional debe ser expresión de la comunidad regional, dicho Presidente del Gobierno regional, debe ser elegido por los consejeros regionales o electo directamente por la ciudadanía regional.

Una descentralización regional efectiva contribuye a generar los contrapesos adecuados del gobierno nacional, lo que exige a su vez una revisión de los recursos autónomos que puedan manejar los gobiernos regionales y que ellos puedan cubrir adecuadamente las competencias atribuidas, las que deben ser adecuadamente revisadas.

Es cuanto puedo informar a vuestra comisión.

13 FLISFISH, Ángel. "Gobernabilidad y consolidación democrática. Sugerencias para la discusión". Revista Mexicana de Sociología, LI, 3, 1989, pp. 113 y ss. 